\title{
بلاغة رد الأعجاز على الصدور في خطب الخلفاء الراشدين ( رضي الله عنهم)

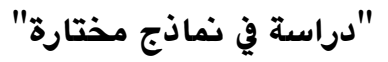

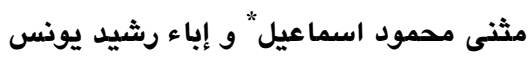 \\ قسم اللغة العربية ، فاكولتي العلوم الانسانية ، جامعة زاخو ، إقليم كوردستان - العراقي
}

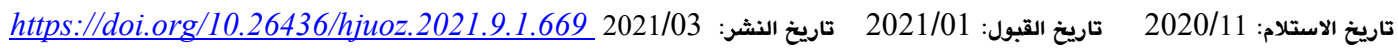

تعد الخطابة من أقدم فنون الأدب، فلا يخلو منها مجتمع من المجتمعات التي حفظ التاريخ آثارها إلى يومنا هذا، لما لها من دود وظيفي

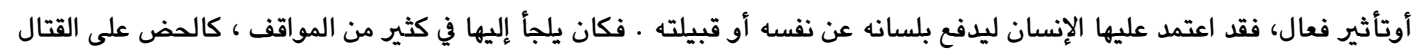

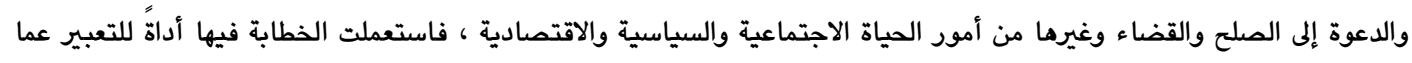

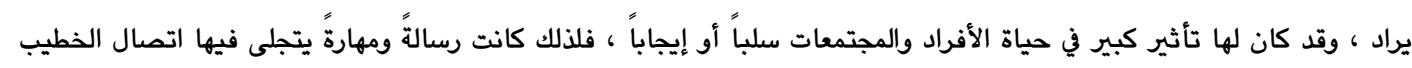

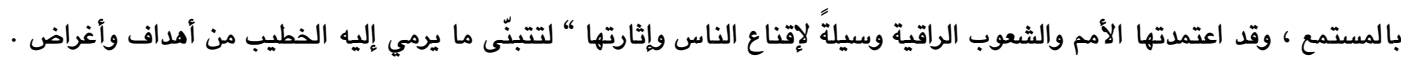

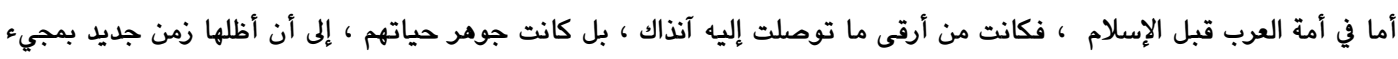

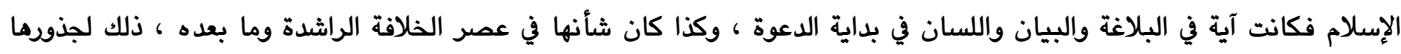

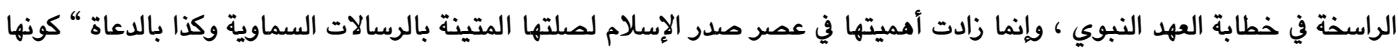

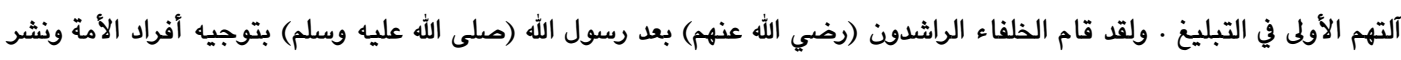

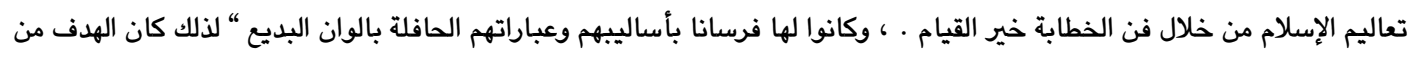

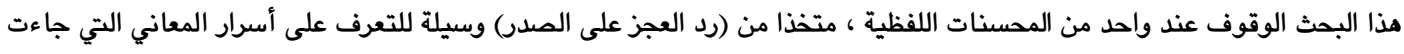
بها تلك الخطب من خلال دراسة وتحليل نماذج منها للوقوف عند كيفية توظيف هذا المحسن اللفظي خطابياً .

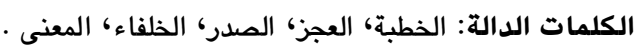

هوامش البحث وقائمة بأسماء المصادر والمراجع التي اعتمدتها الدراسة. 2. التمهيد

الخطبة بين اللغة والاصطلاح : (20) الخطبة لغةً : خَطَبَ : الخَطْبُ : سبب الأمر ، يقول : ما خطْبك ؟ وخطبْتُ على المنبر

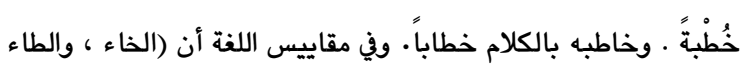

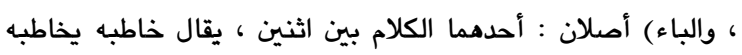

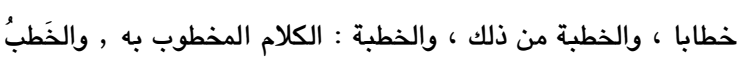
الامر يقع ، وإنما سُمِّي بذلك لما يقع فيه من التخاطب والمراجعة ، وأمّا

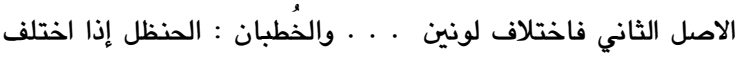

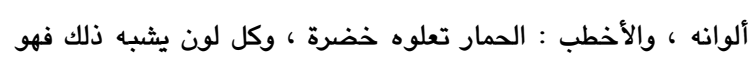

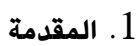

تعددت علوم العربية وتطورت أساليها، ومنها علوم البلاغة (المعاني والبيان والبديع) التي كانت وسيلة ناجحة في كل العصور تمارس فن النيا

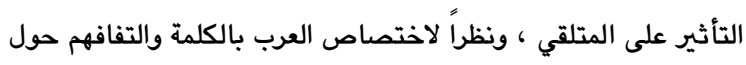
المعنى وتحسين اللفظ ورونقه ، وتفاخرهم في ذلك بأنهم دماة البلاغة البهانة

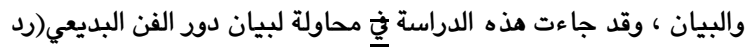

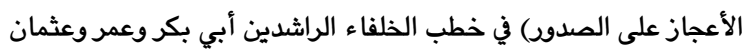

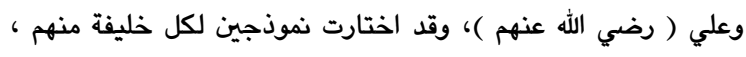

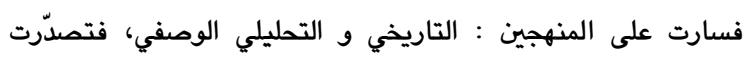

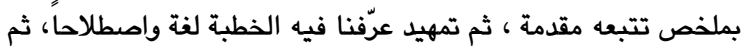

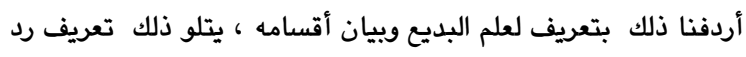

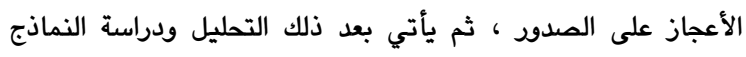

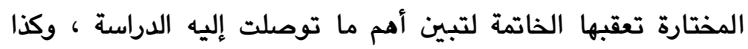


سلامة المعنى في الجملة . منها الجناس والسجع ولزوم ما لا يلزم والموازنة . (13) ومن هذه المحسنات أيضاً : رد الأعجاز على الصدور

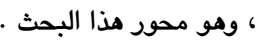

والمحسنات المعنوية : هي الضرب الثاني من فنون علم البديع ، ويكون

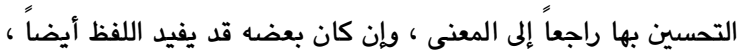
ولعلماء البلاغة في هذه المحسنات وقسيمها جهود علمية ويحثية كثيرة في أنواعها وتفريعاتها وفوائدها للنصوص التي ترد فيها . ويندرج تحت المحسنات المعنوية العديد من التقسيمات منها : الطباق والمقابلة ومراعاة النظير والمبالغة والمذهب الكلامي واللف والنشر والتورية

والتقسيم وغيرها .

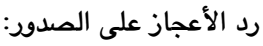
يتألف مصطلح هذا الفن البديعي من عدة كلمات يستلزم بيان كل كلمة بمفردها تباعا : فالرد لغة : معناه العود والرجوع ، تقول (( ردّّ السائل ، وردّه عن حاجته وردّ عليه قوله ... وردّ يده كقولك : مرجوعه ... وارتدّ مبَته : ارتجعها () (14)

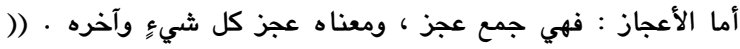
فأعجاز الأمور أواخرها . وعجز البيت خلاف صدره ، وعجّز الشاعر :

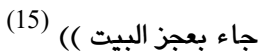
وأما الصدور : فجمع الصدر ، وهو : (( أعلى مقدم كل شيءٍ وأوله ، حتى إنهم ليقولون : صدر النهار والليل ، وصدر الشتاء والصيف ، وما أثبه ذلك ... والصدر واحد الصدود ... وصدر القناة أعلاها ، وصدر الأمر أوله ، وصدر كل شيءً أوله وكل ما واجهك صدرّ ، وصدر الإنسان منه () (16) أما (رد الأعجاز على الصدور) فقد أثار إليه ابن المعتز (ت399هـ)

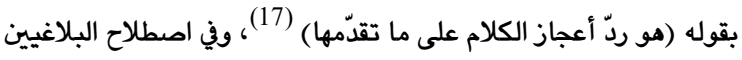
هو : (( في النثر أن تجعل أحد اللفظين المكرين أو المتجانسين أو

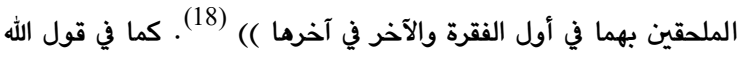

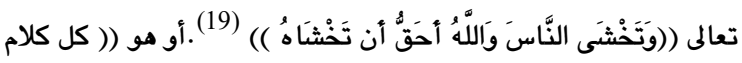
منثور أو منظوم يلاقي آخره أوله بوجه من الوجوه )( (20) والمراد بالمكررين : المتفقين لفظاً ومعنى .ويالمتجانسين : المتشابهين في اللفظ دون المعنى ، ويالملحقين : اللذين يجمعهما الاثتقاق أو شبه الاثتقاق · فهذه أربعة أقسام ، والأمثلة لها على الترتيب فيما يلي :

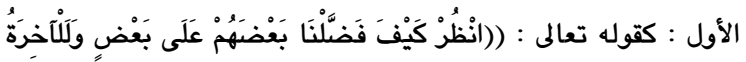

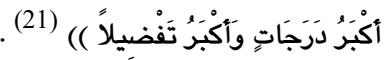
الثاني : كقولك : سائل اللئيم يرجع دمعه سائل .

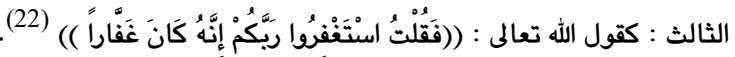

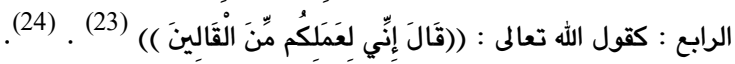
أما في النظم (( فرد العجز على الصدر في الأبيات الشعرية أن يكون أحدهما في عجز البيت والآخر إمّا في صدر المصراع الأول او في حشوه
أخطب والخطبة: مصدر للفعل ، خطب يخطب خُطبة وخطبة ، فالخطبةُ في الكلام، والخطبة لخطبة النساء ـوالخطاب والمخاطبة: مراجعة الكلام. وقد خاطبه بالكلام مخاطبةً وخِطاباً ، وهما يتخاطبان ،واختطب القوم فلاناً ، إذا دعوه الى تزويج صاحبتهم ، والخِطب : الذي يخطب المرأة والجمع أخطاب . ورجل خطّاب كثير التصرُّف في الخطبة ، والخطبة :

كلام منثور مسجوع وهي مثل الرسالة لها بداية ووسط ونهاية . (1 ). الخطبة اصطلاحاً :

تراوح تعريفها اصطلاحا بين القدم والحداثة فيقول عنها أرسطو: إنها ( قوة تتكلف الإقناع الممكن في كل واحد من الأمور المفردة ثم ذكرها ولمح الى صنيعها قائلا : فن القول :يجعل من يملكون ناصيته بارعين في الكلام ، وما دام الكلام تعبيرا عن الفكر“ فإنه يجعلهم أذكياء في شيء ما )). (2) وقال قدامة بن جعفر (ت337هـ) ((إن الخطابة مأخوذة من خطبت أخطب خطابة ، كما يقال كتبت أكتب كتابة ،واشتق ذلك من الخطب ، وهو الأمر الجلل “ لأنه إنما يقام بالخطب في الأمور التي تجل

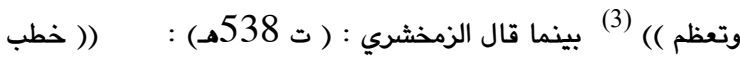
: خاطبه أحسن الخطاب ، ومو المواجهة بالكلام ، وخطب الخطيب

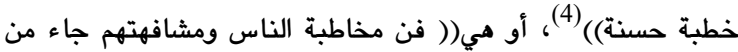
أجل إقناعهم بأفكار يريدون توصيلها اليهم واستمالة قلويهم من خلال الأدلة الموضوعة المقنعة . . .)) (5) وقد عبر عنها الطاهر بن عاشور (ت 1394 هـ) بأنها ((كلام يحاول به الخطيب إقناع أصناف السامعين بصحة غرض في مقصده لفعله أو الانفعال به ، وتشمل المنظوم والمنثور من الكلام " إذ يجوز أن تكون الخطبة كلها نظماً (6).

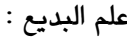
والبديع في اللغة : البدعُ : الأول في كل أمر ، وأمر بديع : مبتدع ، والله

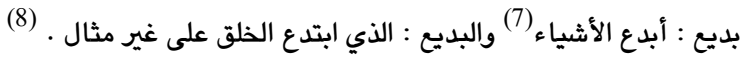

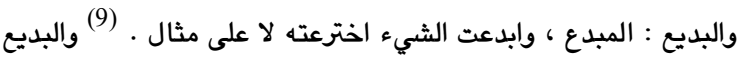
: هو الغريب لكونه لم يكن على مثال سابق . (10).

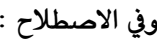
((هو علم يعرف به وجوه تحسين الكلام بعد رعاية تطبيقه على مقتضى الحال ووضوح الدلالة ، وهذه الوجوه ضربان : ضرب يرجع إلى المعنى

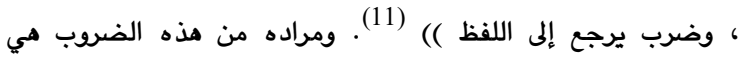

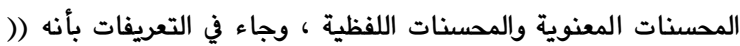
علم يعرف به وجوه تحسين الكلام بعد رعاية مطابقة الكلام لمقتضى

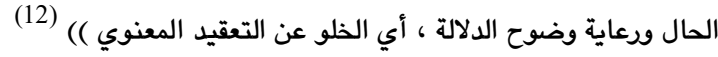
المحسنات اللفظية : هي ضرب من فنون علم البديع وقسيم المحسنات المعنوية ، وتطلق على المحسنات التي تهتم بتحسين اللفظ ، الذي يؤدي بدوره إلى تحسين المعنى أو المضمون ، وقد حدد العلماء هذه

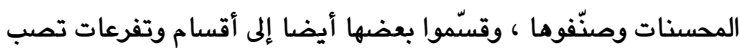
كلها في دائرة علم البديع وما يختص بشكل اللفظ وتزيينه ، مع مراعاة 
تردد ألفاظه ويرجع بعضها إلى بعض فيه تقرير وييان وتدليل ، ونوع

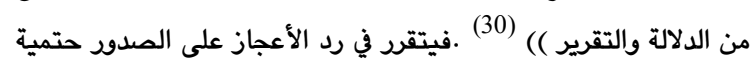
القضاء والقدر الذي لا بد للإنسان أن يخضع له اله ، وتكمن جمالية صور

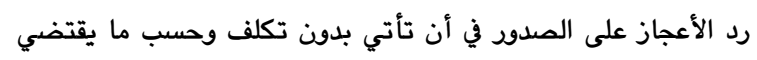
المقام • (31) وعند إنعام النظر في جملتي الصدر والعجز ((فإن محمداً

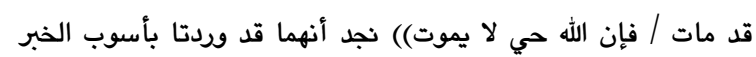

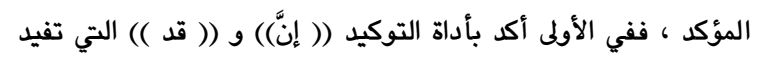

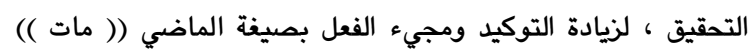
للدلالة على أن الموت قد حصل قبل زمن إلقاء الخطبة وتحقق · بينما نرى في الجملة الثانية الواقعة في موقع العجز مؤكدة كذلك بـ (( إنّ ))

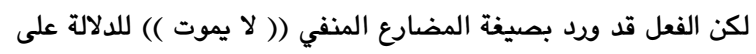
استمرارية الحياة وديمومتها في حق الله تعالى وانتفاء الموت عنه لاستحالته عليه جل وعلا · ويلاحظ أن (( في إيثار التعبير بلفظ الجلالة ( (الله )) دون غيره من أسمائه الحسنى سبحانه “ لإلقاء المهابة والجلالة والتعظيم في نفوس المخاطبين )(32) وإن كانوا يهابونه ويعظمونه في نفوسهم ، لكن ريما اختلت بعض النفوس في تلك الحالة فذكّرهم بعظمة الخالق جل في علاه ، وأنه تعالى منزّه عن الموت وسائر ما يعتري الإنسان من أعراض . ومذا النص بعمومه الذي سيق في حلة رد العجز على الصدر يحمل معنى الآية ( 144 / آل عمران ) التي ارتكزت عليها المعاني المقصودة منه . وكذلك ورد رد العجز على الصدر في نص آخر من خطبة له (رضي الله عنه) يخاطب فيها الأنصار حينما ورد مال البحرين بعد أن وجدوا في

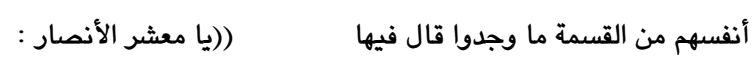

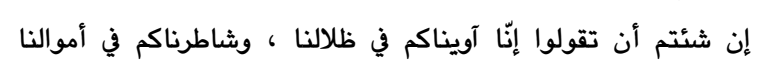

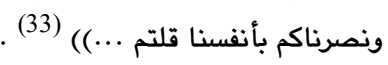
فقد رد العجز في (( قلتم )) على الصدر في قوله (( تقولوا )) ومما لفظان

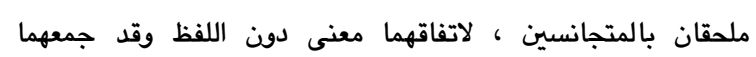

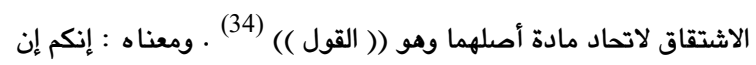

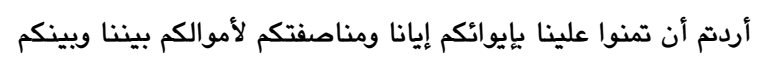

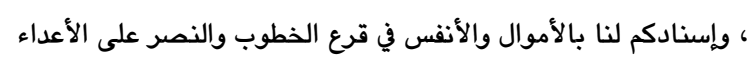

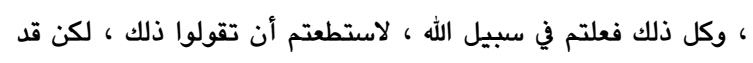

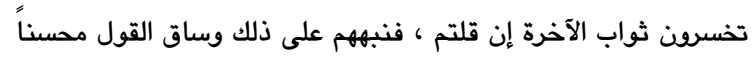
إياه برد العز على الصدر فكان فيه (( تذكير وروابط من ( روابطه بحيث ) يستطيع السامع أن ينطق باللفظة الأخيرة أو بالشطر الأخير

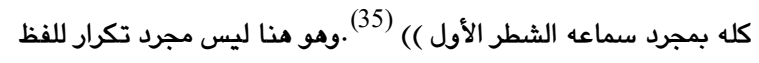

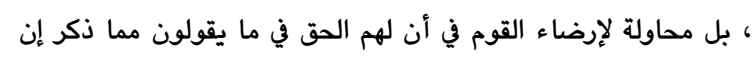

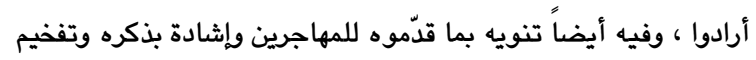
له في القلوب والأسماع ، من أن الذي قدّمه الأنصار للإسلام والمسلمين

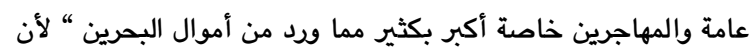

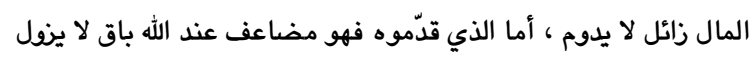

أو في عجزه ، وإمّا في صدر المصراع الثاني. وعلى كل من هذه التقادير

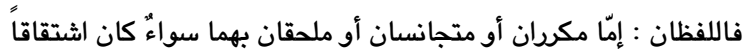
أو شبهه () (25) فالفظان : أما مكرران.

رد الأعجاز على الصدود في خطب الخلفاء الراشدين ( رضي الله عنهم): ورد فن رد الأعجاز على الصدود في خطب الخلفاء الراشدين (رضي الله عنهم) ووظفوه في أغراضهم ومقاصدهم ، مستثمرين طاقاته الموسيقية

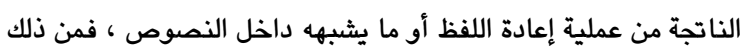
ما ورد في خطبة سيدنا أبي بكر الصديق (رضي الله عنه) يوم قبض من من رسول الله (صلى الله عليه وسلم) إذ خرج إلى الناس وهم في شديد غمرتهم فخطب فيهم بقوله (( أيها الناس : من كان يعبد محمداً فإن إن

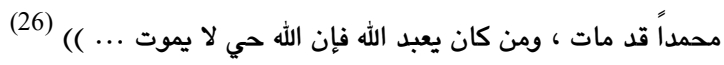
فقد رد العجز على الصدر في موضعين : الأول في قوله ((ومن كان يعبد )) في صدر العبارة الثانية، حيث ردّه على قوله ((من كان يعبد )) الذي في صدر الكلام بعد النداء ، والثاني في قوله ((لا يموت)) الذي في العجز على قوله ((مات)) ، ففي الفقرة الأولى ثلاث كلمات توافقت فيها الألفاظ مع معانيها ، أما في الفقرة الثانية من كلامه أورد لفظتين متقابلتين فرد التي في العجز على التي في الصدر ، واللفظتان ملحقتان بالجناس ، فقد مند جمعهما الاثتقاق · إذ أن اللفظتين ترجعان إلى أصل لغوي واحد وهو

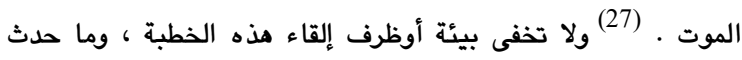
للناس من حالة نفسية صعبة أبت أن تسعف أكثر الناس في تصديق ما واء إمداء قد حصل “ لذلك كان لابد من كلام يطابق مقتضى الحال فلجأ الخليفة إلى القرآن الكريم الذي آمن به المخاطبون وصدّقوه ، فاستند إلى قول

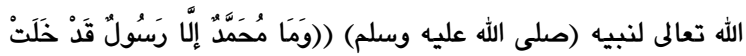

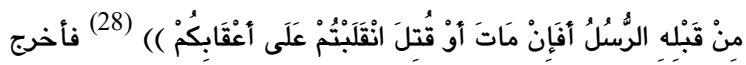
منها معاني خطبته وألقاما على المخاطبين بأسلوب رد العجز على ماتى الصدر ((لتأكيد المعنى وتقريره ، وذلك بإعادة اللفظ مرة ثانية ثم الارتباط بين أجزاء الكلام بدلالة آخره على أوله وهو من بديع النظم))

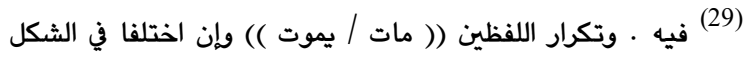
لكنهما متفقان في المعنى ، وأراد الصديق ( رضي الله عنه ) أن يذكّر الناس ويؤكّد لهم أن رسول الله (صلى الله عليه وسلم) لمّا كان بشراً

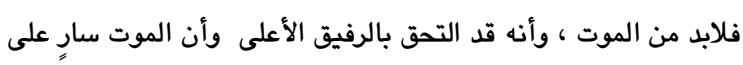

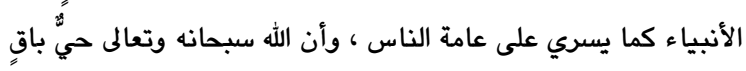
لا يعتريه الموت “ لاستحالة ذلك عليه جل وعلا ولأنه تعالى هو خالق الموت والحياة ـ وهذا الأسلوب (( ما يفيد من البلاغة مثل ما أفاده

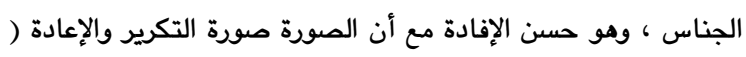

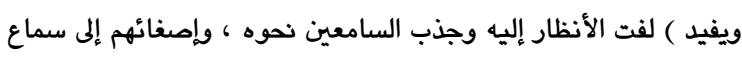
هذه الألفاظ المكرة ( المتفقة ) المعنى فيتمكن المراد في القلب ويقوى في الوجدان . . ( وكذا ) يقوي المعاني لإعادة الألفاظ مرة ثانية ، كما يجمل الألفاظ بما يحمله من رنين موسيقي وانسجام بين لفظين بينهما اتفاق ( معنوي ) كما يعمل الفكر ويشوق السامع إليه ، فالكلام الذي 
مقدمة وسبب لقوله : ( لولا رجاء أن أكون خيركم . . . ما توليت

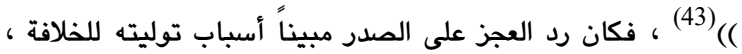

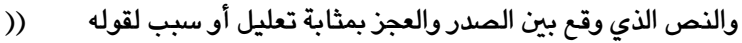
توليت )) “ لذلك جاء النص متسقاً دلالةً وتركيباً ، فهو يترتب على على إجراءات تبدو بها العناصر السطحية على صورة وقائع يؤدي الصدر منها إلى العجز فيها بحيث يتحقق فيه نوع من الترابط الرصفي ، ويه

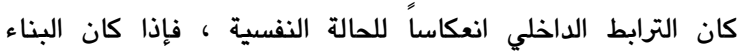

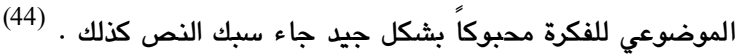
وقد أعلن الخليفة عمر (رضي الله عنه) من خلال هذا النص وتكرار معنى الولاية بين كل من الصدر والعجز عن أمليته وأحقيته بها للأسباب التي ذكرها ، وفيه أيضاً إثارة إلى من قد يكون معارضاً من المخاطبين لهذا الأمر في أنه ليس مؤملاً لتقليده الخلافة . وورد أيضاً رد العجز على الصدر في نص آخر من خطبة للفاروق (رضي الله عنه ) حينما كان يقسم الأموال على أهل المدينة ، جاء فيها قوله : ( (... ثم من أسرع إلى الهجرة أسرع إليه العطاء ، ومن أبطأ عن الهجرة أبطأ عنه العطاء ... () (45) فقد رد العجز على الصدر في كل من الفقرتين بين ألفاظ متعددة بنفس الصورة والمعنى من غير تغاير أو تفاوت بين الألفاظ ، ففي الفقرة الأولى (من أسرع إلى الهجرة أسرع إليه العطاء ) رد لفظة (أسرع ) الثانية على الأولى بصورتها ومعناها ، وفي الفقرة الثانية (ومن أبطأ عن الهجرة أبطأ عنه العطاء ) رد لفظة (أبطأ ) الثانية على الأولى كذلك ، وعلى مستوى الفقرتين نجد أنه رد لفظة ( العطاء ) التي في عجز الكلام إلى التي في الصدر .فكل الأعجاز التي ردت على الصدور في هذا النص كانت بصورتها ومعناما مطابقة في اللفظ والمعنى (46) . والذي يفهم من النص أن عمر ( رضي الله عنه ) ( كان يفاضل في العطاء على حسب البلاء في الإسلام والقدم فيه ، والغناء والحاجة ، ويفضل من شهد بدراً على غيره

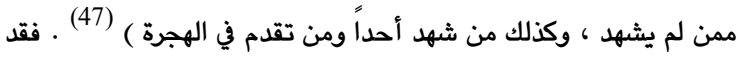
كانت بين صدر كلامه والعجز رابطة لفظية واضحة حصلت بها الملائمة ) والتلاحم بين الفقرتين · وقال أبو ملال العسكري ( ت 395ه )

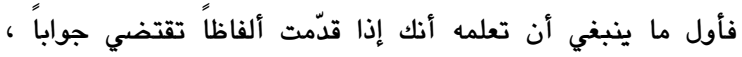

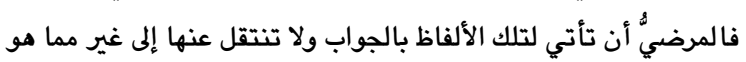

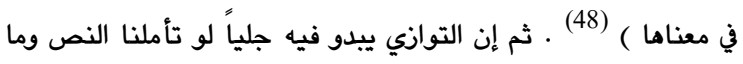
صاحبه من رد الأعجاز على الصدود بنظر دقيق ، وإن كان ( التوازي لا يعني تكرار عناصر متساوية فحسب ، وإنما يعني العناصر المتعارضة والمتضادة أيضا . حيث تحكمه المشابهة وعدم المشابهة والترادف والتخالف ، فالأصوات المتماثلة أو المتشابهة أو المتضادة و وكذا ) ...التراكيب ذات العناصر النحوية المتشابهة أو المتعاكسه كلها يمكن أن تشكل مظاهر للتوازي بأنواعه ) (49) فالألفاظ المكررة في قوله ( أسرع ) (وأبطأ ) ( والعطاء ) يتوخى فيه شكل خاص للنص لابتغاء الشكل الفني والجمالي المتولد من رد العجز على الصدر
(36) وليقر ذلك في النفوس ، وقد أسهم رد العجز على الصدر في ابراز مذا المعنى “ لأن وظيفته ( تأكيد المعاني وتقريرها في النفوس “ ذلك أن اللفظ عندما يذكر أول الفقرة ثم يكرد في عجز الكلام ، فإن هذا يؤدي إلى تأكيد المعنى وتقريره في ذهن السامع ... ( وهو ) من أسباب ترابط الكلام وتلاحم أجزائه ، فأوله يدل على آخره وآخره مرتبط بأوله )

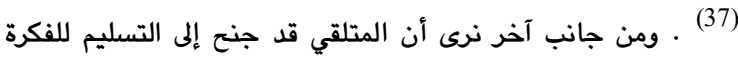
والقبول بها وذلك (( من خلال إدراك أن التعبير عن الفكر ... يمثل لوناً من الاتصال ، وذلك بافتراض مسبق لوجود نشاط من المتكلم ونشاط مستقبل من المرسل إليه ، وقد يكون مذا الاتصال موضوعيا خالصاً ، لكنه غالباً ما يضاف إليه الرغبة في التأثير على المرسل إليه ، فكل جماليات النص تمثل وسيلة أكيدة لكسب مودة المخاطب )) (38)فقوله (رضي الله عنه) : (( لو شئتم أن تقولوا . إلى قوله ... قلتم )) دفع بالواجدين في أنفسهم إلى القناعة والرضوخ لما سمعوه “ لأنهم وجدوا في

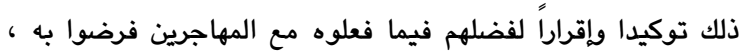
وتأثرت النفوس فاستجابت . وكذلك ورد رد الأعجاز على الصدود في خطب سيدنا عمر بن الخطاب (رضي الله عنه) ، فمن ذلك ما ورد في خطبته بعدما ولي الخلافة جاء فيها قوله : (( أيها الناس : إني قد وُلّيت عليكم ولولا رجاء أن أكون

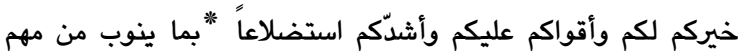

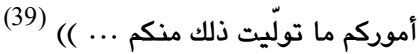
المشهد هنا مشهد تولية الحكم ولهذا كان التأكيد على هذا الأمر بتكراره، وفي خطبة أبي بكر الصديق(رضي الله عنه) كان المشهد مشهد الموت ولهذا ركز عليه بتكراره لتوصيل رسالته حول هذا الموضوع على وجهها الصحيح، فوقع رد العجز على الصدر بين قوله ((توليت)) التي في العجز و (وليت)) التي في الصدر فاللفظان مكرران لفظاً ومعنى

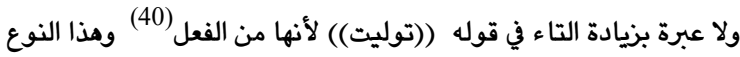
أطلق عليه ابن أبي الإصبع المصري (ت 654 هـ) بتصدير الطرفين(41) وهو نوع من الفلسفة اللغوية لأساليب التواصل الإقناعي ، ويدل على

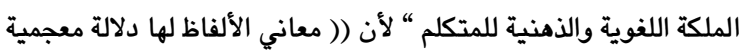
وهذه الدلالة نابعة من المستوى الذهني الذي يكيف التقاطنا للتجرية))(42) لذلك نجد أن التنظيم النصي الذي يقيمه الخليفة (رضي الله عنه) من خلال رد العز على الصدر امتداد لتصوره المنظم للمحيط الخارجي ووعيه المدرك له ،(( فمراعاته لإحراز المنفعة على موافقة الحال وحرصه أن يكون معناه ظامراً مكشوفاً وقريباً معروفاً عند الخاصة والعامة جعله يدقق في فعالية الكلمة وما يتولد عنها من دلالات ، وكيف تزيد مذه الدلالات أو تنقص نتيجة لعلاقة الكلمات بعضها ببعض ... لذلك نجد نوعاً من العلاقات التلاؤمية التي تربط بين الوحدات اللغوية فيأتي جزء منها مقترناً بجزء آخر بحيث إذا ذكر الأول ورد الثاني ، ويأتي قسم منها بمصاحبة الآخر بحيث إذا ورد الأول استدعي الآخر .. فمجيء قوله (أيها الناس : إني قد وُلّيت عليكم ) 
وقوله (فلا أنزع ) يشي بالقوة والسلب في الشيء والقلع ، وهو أكثر ما

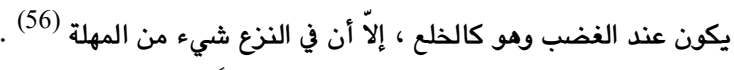
لذلك كان معنى ( فلا أنزع ) التي في الصدر مغايراً لمعنى الذي في العجز

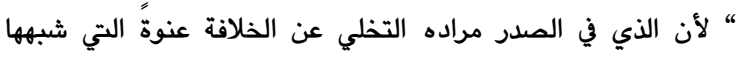
بالقميص ، فصاحبه العنف والإجبار والقوة ، بخلاف معنى لفظة ( أنزع ) التي في العجز “ لأنها تخلو من العنف أو الاضطرار إليه ، فهو ينزع باختياره ومحض إرادته ، لكن ليس في الخلافة ، وإنما فيما يسوء الناس باعتقادهم من أمور الخلافة على أن لا يعود إليها ، لذلك كان اللفظان مشتركين في معنى النزع لكنهما متغايران في طريقة إجراء النزع مع اختلاف ماهية الشيء المراد انتزاعه ، فكان لكل لفظ منهما معناه في العجز والصدر حسب السياق “ ذلك أن السياق إضافة إلى دوده في تفسير النصوص ومعرفة مرادها ، له دور كذلك في تحديد وتوضيح الدلالة كونه (( يرشد إلى تبيين المجمل وتعيين المحتمل ، والقطع بعد احتمال غير المراد ، وتخصيص العام وتقييد المطلق وتنوع الدلالة ،

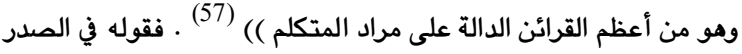

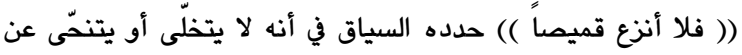

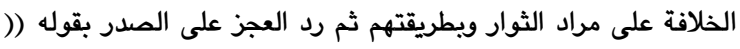
لكني أتوب وأنزع )) بطريقته هو عن الأمور التي أغضبتهم في سير الخلافة ، فهو نزعٌ مغاير لنزع الثوار له ، وعليه يمكن القول أن رد العجز على الصدر يشويه نوع من القبول بمعنى النزع ، شرط أن لا يكون في الخلافة ، بل في أمور تتعلق بالخلافة والتي أغضبت المعارضين ، مذا

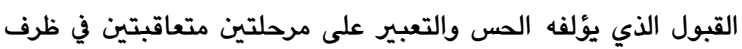
إلقاء الخطبة “ لأن الحس والشعور سابق في نفس صاحبه ثم يليه التعبير عنه في صورة لفظية (58)، وقد عبر الخليفة (رضي الله عنه) عن مذا الموقف من خلال الالتجاء إلى فن رد الأعجاز على الصدور وتوظيفه لأداء غرضه بشكل جمالي ((من خلال الاعتماد على علائق وترابط بين الكلمات تؤلف بينها بنسيج جديد ، كما أنه يضفي بعض سمات الشيء

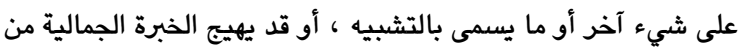
خلال حسن وصف (المتكلم) للأشياء وكل هذا يحرك ملكات التلقي

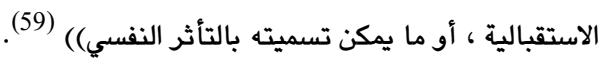
وقد ورد رد الأعجاز على الصدور كذلك في خطب سيدنا علي بن أبي طالب (رضي الله عنه وكرم وجهه) كالتي رد فيها على رجال أشاروا إليه بتأجيل قتال أهل الشام ، جاء فيها قوله ((أما بعد : فإن الله وارث العباد والبلاد ، ورب السموات السبع والأرضين السبع وإليه ترجعون ، يؤتي الملك من يشاء وينزع الملك ممن يشاء ، ويعز من

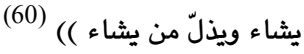
تلاحظ في هذا النص جمل متتالية ردت فيها الأعجاز على الصدود وهي ((ورب السموات السبع والأرضين السبع )) فقد رد لفظة (السبع ) التي في العجز إلى التي في الصدر، وفي ورود قوله ((السموات السبع والأرضين السبع )) تهويل للمشهد ، أما جملة ((يؤتي الملك من يشاء وينزع الملك
وكذا ورد رد الأعجاز على الصدود في خطب سيدنا عثمان بن عفان (أن رضي الله عنه ) كما في خطبته التي ألقاما في الناس بعد أن بايعه أهل الشورى ، قال فيها : ((... ألا وإن الدنيا طويت على الغرود ، فلا

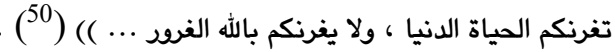
فرد العجز على الصدر ورد في مواضع في كل من ( الدنيا / الغرود / تغرنكم ) فرد لفظة ( الدنيا) من عجز الفقرة الثانية على التي في صدر الأولى ، ورد لفظة ( الغرود ) من عجز الفقرة الأخيرة إلى التي في الفقرة الأولى ، ثم رد لفظة ( لا يغرنكم ) من الفقرة الأخيرة إلى التي في صدر الفقرة الثانية مع تغيير حرف المضارعة من (الياء إلى التاء) . والنص

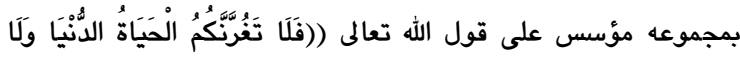

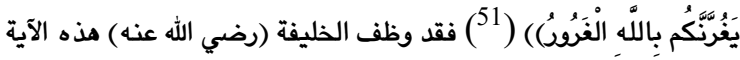
لإسهامها في تحقيق رد العجز على الصدر وتقوية قوله “ ولذلك يبدو في النص نوع من المحاذاة أو التناظر يقوم عليه ، حيث تركيب القول من جزأين وكل واحد مهنما موافق للآخر في المادة والمثال وكل جزء منهما يدل على معنى هو عند الآخر بحال ملائمية وقد أخذا من جهتي وضعهما في الجنس الملائمي من الأمود ووضع أحدهما صدراً والآخر عجزاً مردوداً

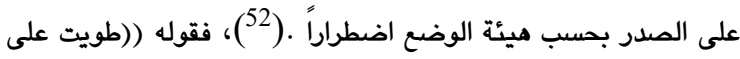
الغرور)) رد إليه قوله ((ولا يغرنكم بالله الغرو)) بحسب ميئة الوضع والاضطرار إليه . وكذا في قوله ((ولا يغرنكم )) حيث رد من عجزه إلى لى إلى صدره ((فلا تغرنكم ))، وقد أكد الخبر ونبه إليه بلفظة (( ألا )) في صدر الكلام ، وحذّر من الاغترار بالدنيا بقوله ((فلا تغرنكم الحياة الدنيا (إن)

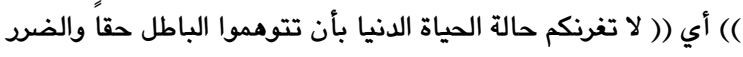

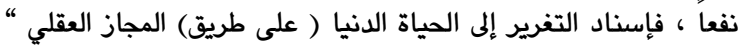
لأن الدنيا ظرف الغرود أو شُبْهُه ، وفاعل التغرير حقيقة هم اللذين يضلونهم بالأقيسة الباطلة فيشبهون عليهم إبطاء الشيء باستحالته ، فذكرت هنا وسيلة التغرير وشبهته ثم ذكر بعده الفاعل الحقيقي للتغرير وهو الغرود · · والمراد منه الشيطان بوسوسته وما يليه من نفوس

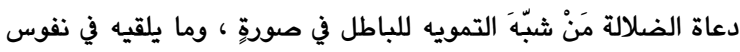
أتباعهم من قبول تغريرهم ، وعطف (ولا يغرنكم بالله الغرود ) لأنه أدخل في تحذيرهم ممن يلقون إليهم الشبه ، أو من أوهام أنفسهم التي

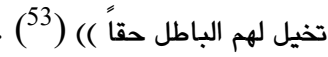
وقد ورد هذا الفن في نص آخر من خطبة له (رضي الله عنه) رد فيها على الثائرين عليه جاء فيها قوله : ((... فلا أنزع قميصاً قمّصنيه الله عز وجل وأكرمني به ، وخصّني به على غيري ، ولكنّي أتوب وأنزع ، ولا أعود لشيء عابه المسلمون ...)( فقد رد العجز في قوله ( وأنزع ) على ما استفتح به في قوله (فلا أنزع ) فقد بدأ به ثم كرده في عجز كلامه . على طريقة طباق السلب لاختلاف المعنى (( فكان العجز مدركاً والنهاية والآخِر، بدلالة فاتحة القول ومقدمته وصدره عليه ، وذلك ضرب من اللزوم ونوع من المناسبة ...

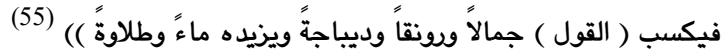


الإمام (عليه السلام) للمخاطبين الذين نصحوه التأني في القتال على

الخلاف الذي نشب بينه وبين معاوية (رضي الله عنهما) . وفي نص آخر من خطبة له ( رضي الله عنه وكرم وجهه ) ورد فن رد العجز على الصدر ، وهي خطبته التي خطبها في الخوارج حينما اعترضوا على التحكيم ، جاء فيها قوله ((...إنّا لم نحكّم الرجال ، وإنّما حكّمنا

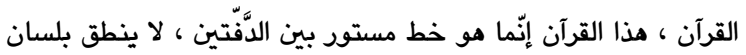

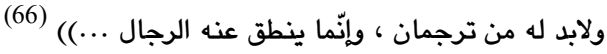
فرد لفظة ( الرجال ) التي في عجز الكلام على التي في الصدر ، وكذا لفظة ( القرآن ) ردما إلى التي قبلها في الصدر ، ويهذا النص رد على الخوارج ومعناه (( إنا لم ندكّم الرجال أي : كونهم رجالاً ، ولكن حكّمنا

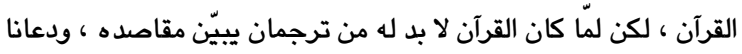
القوم إلى حكم القرآن ، ولم نكن نحن الفريق الكاره لكتاب الله المتولي عنه بعد أمره تعالى بالرجوع إليه وإلى رسوله في الكتاب والسنة فيما

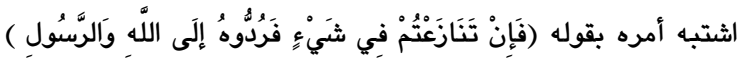

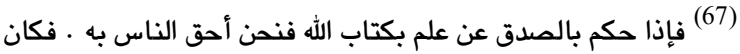
الحاكم لهم مخطئًا مخالفاً لكتاب الله غير عامل به فوجبت مخالفة حكمه ... وخلاصة هذا إنا لم نرض بتحكيم الرجلين ، ولكن بتقدير حكمهما بكتاب الله الذي مما ترجمان عنه ، وهو الحاكم الذي دعانا الخصم إليه

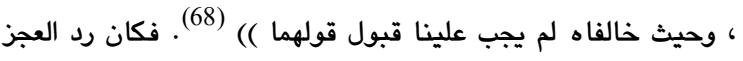
على الصدر أشبه ما يكون بوثاق رقيق ، أو نغمة موحدة تربط طرفي الكلام ويضفي على النص من إيقاع داخلي ( مؤداه ربط المعاني بعضها ببعض من خلال تقرير المعنى بترديد اللفظ ومجيئه (موافقا) للفظ الآخر ، مما يؤكد معناه في الذهن ويقرد الدلالة التي يرمي إليها . . ومذا يعزز الدور المعنوي الذي ينهض به أسلوب (رد العجز على الصدر) الذي يرستخ المعاني بين طرفين مترابطين بعلاقة توافقية محكمة ينتج عنها إيقاعاً صوتياً يوحّده (التطابق اللفظي) الجامع والبارز في المستوى الخارجي لوحدتين صوتيتين مكررتين لإيصال بعد دلالي أعمق يفصح

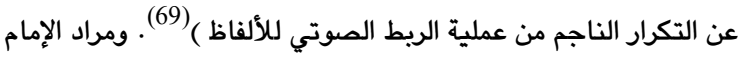
( عليه السلام ) برد العجز على الصدر تقرير المعنى المستكن في نفسه

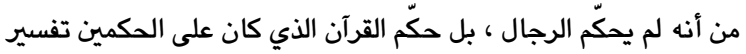
ما في القرآن من آيات تعالج الأمور في مثل هذه المواقف وفي ترجيع لفظة

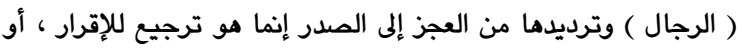
رد على المعنى الذي تقرد في نفوس الخوارج بنفس لفظة ( الرجال ) وهو جزء من النص داخل في أصول جمالية فن رد العجز على الصدر .

\section{3. نتائج البحث}

ولقد توصل البحث إلى نتائج منها : 1- مجيء رد العجز على الصدر بمستويين في خطب الخلفاء الراشدين هما : اللفظ الواحد ، والألفاظ المتعددة ، فمن اللفظ الواحد في قول
ممن يشاء )) فقد رد فيها لفظتي ( الملك و/ يشاء ) في العجز إلى اللتين في الصدر. والجملة التي تليها مثلها. والمراد من النص التعريض بالناصحين أو مريدي التأجيل ، بأن اعتراضهم إنما هو الجهل بمقادير الله تعالى وأنه هو المتصرف في ملكه فقوله ((يؤتي الملك من يشاء )) محمول على جميع أنواع الملك الذي منه النصر وتولي أمور العامة “ لأن اللفظ عام يحتمل ذلك . ومنهم من بين وجه احتمال اللفظ بقوله () ويحتمل وجهين : أمر ملك الأموال والعبيد، وذلك مما يجوز أن يؤتيه الله للمسلم والكافر ،والآخر : أمر التدبير وسياسة الأمة ، فهذا مخصوص مص وله به المسلم العدل دون الكافر والفاسق، وسياسة الأمة وتدبيرما متعلقة بأوامر الله تعالى ونواهيه)) (61). مذا المعنى الثاني هو الذي أراده الإمام

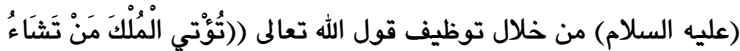

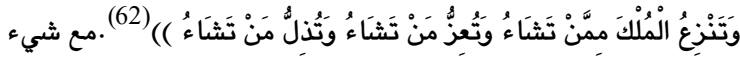
من التصرف بتغيير حرف المضارعة في الأفعال الواردة فيها ـ وهو الجزء الذي يحمل المعاني المقصودة من كلام الإمام (رضي الله عنه))

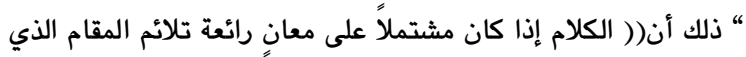
قيلت فيه ، فإن تلك المعاني ستحقق فائدة للمتلقي ، فإن أضيف إلى هذا الكلام شيء من التحسينات الكلامية فسيكون الإنصات له أكثر والإفادة له أوفر)(63) لا سيما إذا كانت هذه التحسينات بطريق بديعي كفن رد الأعجاز على الصدور ، وما يتميز به من الجرس والإيقاع ، فتزيد النفوس إقبالا على النص وما اشتملت عليه “ لأنها جمعت الفائدة

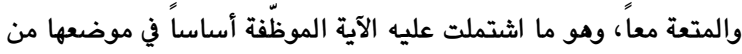
القرآن الكريم، والإيقاع سمة ظاهرة في التحسين البديعي ، وقد رد العجز على الصدر بالألفاظ بصورتها ومعانيها تأكيدا وإقراراً للمعاني التي تحملها ، وإنما يفعلُ ذلك للدلالة على العناية بالشيء حينما يقتضي المقام ذلك ويستلزمه . (64) ومراد الإمام من خلال توظيف الآية وما ورد فيها من رد الأعجاز على الصدور أن يذكّر المخاطبين بأن سلطان الله أعلى من كل سلطان وأن له القوة المطلقة ( والتصرف التام في تدبير الأمور وإقامة ميزان النظام العام في الكائنات (فهو الذي) يؤتي الملك لمن يشاء من عباده ، إمّا تبعاً للنبوة كما وقع لآل إبراهيم ل عليه السلام) وإمّا بالاستقلال بحسب السنن الحكيمة الموصلة إلى ذلك ، واتباع الأسباب الاجتماعية بتكوين القبائل والشعوب. وينزع الملك ممن يشاء بانحراف الناس عن الطريق السوي الحافظ للملك من العدل وحسن السياسة وإعداد القوة بقدر المستطاع ، كما نزعه من بني إسرائيل وغيرمم بظلمهم وفسادهم ، ويعز من يشاء ويذل من يشاء ، فللعزة آثار وللذل مثلها . . والذليل يرضى بالضيم والمهانة ويضعف عن حماية الحريم ومقاومة المهاجم ، ولا عز أعظم من عز الاجتماع والتعاون على لـ نشر دعوة الحق ومقاومة الباطل ، إذا سار المجتمعون على السنن التي سنها الله لعباده ، فأعدوا لكل أمر عدته ، ولا عبرة بكثرة عدد الأمة

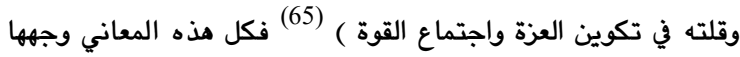


لبديع في ضوء أساليب القرآن : عبدالفتاح لاشين ، دار الفكر العربي ، القاهرة ، 1999

البلاغة العربية أسسها وعلومها وفنونها : عبدالرحمن حسن الميداني ، دار القلم ،

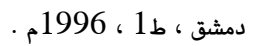

البلاغة الغنية : علي الجندي ، مكتبة الأنجلو المصرية ، مصر ، ط2 ، 1966م

البلاغة القرآنية في تفسير الزمخشري وأثرها في الدراسات البلاغية : محمد أبو موسى

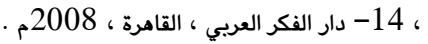

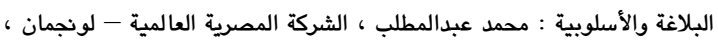

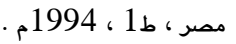

16- البلاغة والنقد : محمد بن علي الصامل وآخرون : وزارة التربية والتعليم ،

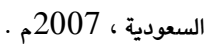

تاج العروس في جواهر القاموس : محمد بن محمد بن عبدالرزاق المرتضى الزبيدي ، الزبي

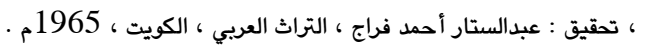

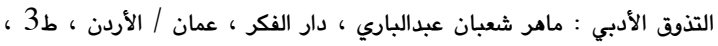

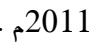

التعريفات : السيد الشريف علي بن محمد بن علي الجرجاني ، تحقيق : محمد باسل

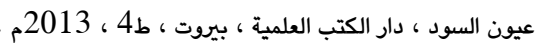

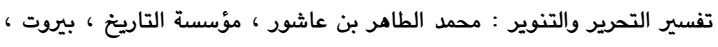

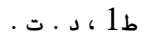

تفسير المراغي : أحمد مصطفى المراغي ، شركة مصطفى البابي الحلبي وأولاده

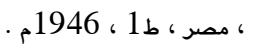

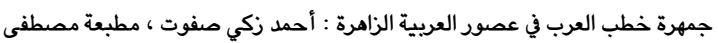

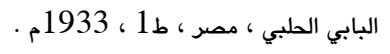

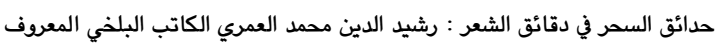

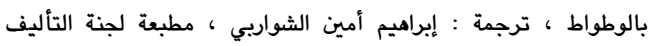

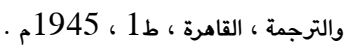

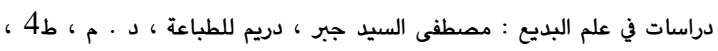
. 2007

شرح نهج البلاغة : كمال الدين ميثم بن علي بن ميثم البحراني ، دار الحبيب ،

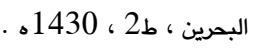

صحاح اللغة وتاج العربية : إسماعيل بن حماد الجوهري ، داه ، لمار المعرفة ، بيروت ،

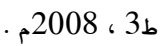

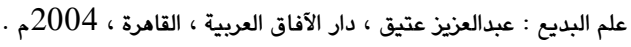

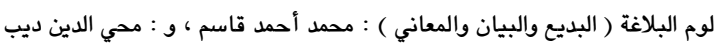

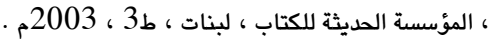

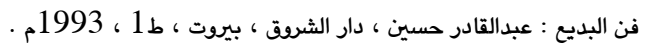

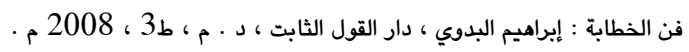
قانون البلاغة في نقد النثر والشعر : أبو طاهر محمد بن حيدر البغدادي ، تحقيق :

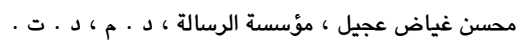

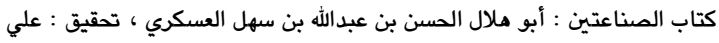

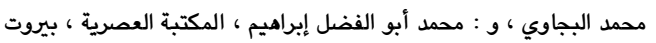

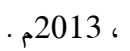

لسان العرب : محمد بن مكرم بن علي ابن منظور ، دار إحياء التراث العربي ،

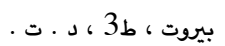

سيدنا الصديق ( رضي الله عنه ) ( من كان يعبد محمداً فإن محمداً قد مات ، ومن كان يعيد الله فإن الله حي لا يموت ) فقد رد لفظة ( يموت

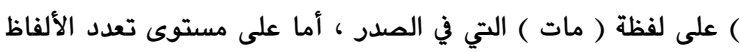
فقد رد قوله (من كان يعبد ) الذي في العجز على الذي في الصدر ، فرد

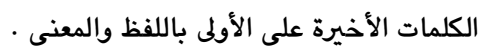

2 - اجتماع بعض المحسنات اللفظية مع المعنوية في نص واحد كالجناس والاقتباس وهما محسنان لفظيان قد اجتمعا مع رد العجز على الصدر ، فمثال الجناس قول سيدنا الصديق (رضي الله عنه) ((إن شئتم أن تقولوا ... قلتم)) فرد(قلتم)على(تقولوا) وهو جناس فول أيضاً جمعهما الاثتقاق ، لأن أصلهما واحد وهو ( القول ) ، وأما مثال الاقتباس فكقول سيدنا عثمان بن عفان (رضي الله عنه)((فَلَّا تَغُرَنَّكُُ

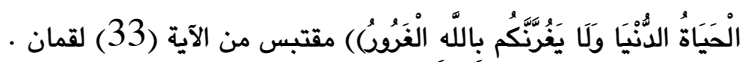
وقول سيدنا علي (رضي الله عنه) ((يؤتي الملك من يشاء وينزع الملك ممن يشاء ، ويعز من يشاء ويذلّ من يشاء)) مقتبس من الآية ( 26 )

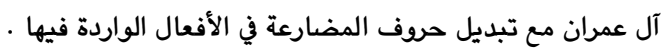
3 - تأثر الخلفاء الراشدين بأسلوب القرآن الكريم وهيمنة الألفاظ الإسلامية على خطبهم مصحوية بألوان البديع التي حفلت بها الآيات القرآنية ، وتوظيف فن رد الأعجاز على الصدور وما يصحبه من بن الإمكانات والخصائص التي تعمل في السياق والمقام ، لإقناع الناس واستمالتهم إلى مراد النص بمساندة الآيات الكريمة .

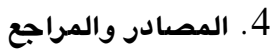

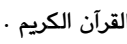

أحكام القرآن : أحمد بن علي الرازي الجصاص ، تحقيق : محمد الصادق قمحاوي

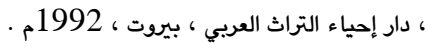

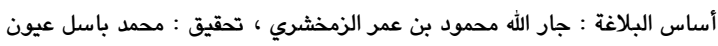

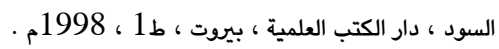

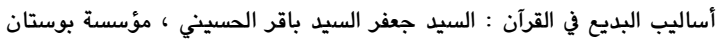

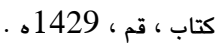

الأسلوبية وخصائص اللغة الشعرية : مسعود بو دوخة ، عالم الكتب الديث ،

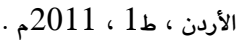

أصول الإنشاء والخطابة : محمد الطاهر بن عاشور ، تحقيق : ياسر حامد المطيري

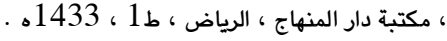

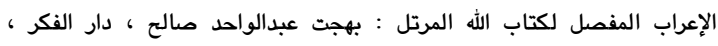

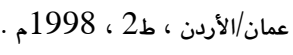

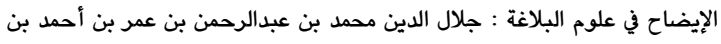

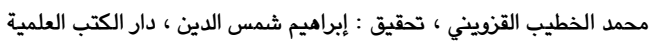

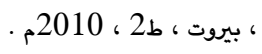

بدائع الفوائد : محمد بن أبي بكر بن أيوب ابن قيم الجوزية ، تحقيق : علي بن

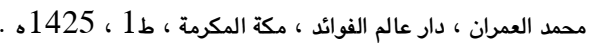

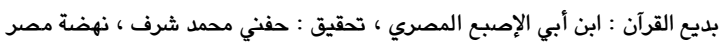

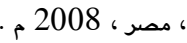




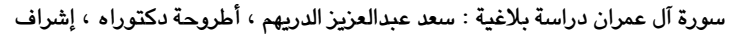

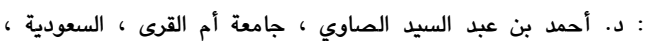

المظاهر البديعية وأثرها الأسلوبي في التعبير القرآني : هدى صيهود زنزود العمري

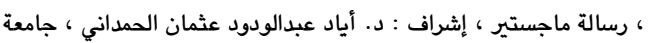

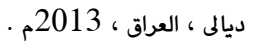

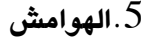

1

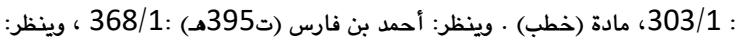

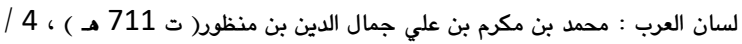

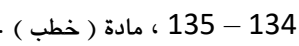

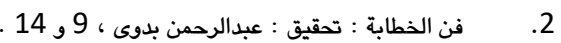
3

أساس البلاغة : جارالله الزمخري: 1 / 255.

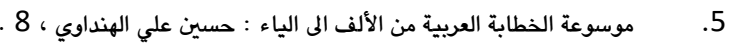

6. أصول الإنشاء والخطابة: محمد ، 119.

7.

8. المخصص في اللغة : علي بن الحسن بن اسماعيل النحوي ( ابن سيده ) : :

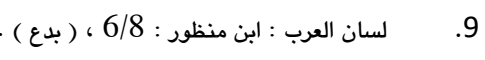

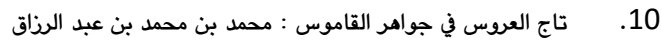

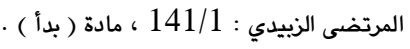

11.

12. الشريف الجرجاني : 158

13. ينظر : علم البديع : محمود المراغي : 149 - 150 . 150

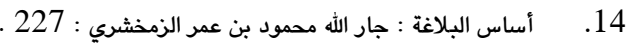

15.

16.

17.

18. الايضاح في علوم البلاغة : الخطيب القزويني : 360 .

$$
\text { 19. }
$$

20. نهاية الأرب في فنون الادب : شهاب الدين احمد بن عبد الوهاب النويري :

$$
\begin{aligned}
& \text { 21 . 21 } \\
& \text { 22. }
\end{aligned}
$$

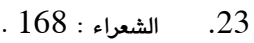

$$
\begin{aligned}
& \text { 24. ينظر : فن البديع : عبد القادر حسين : } 123 \text { - } 124 \\
& \text { 25. اساليب البديع في القرآن : السيد جعفر السيد باقر : } 550 \text { : } \\
& \text { 26. جمهرة خطب العرب : احمد زكي صفوت : } 1 \text { / / } 67 \text { : } 67
\end{aligned}
$$

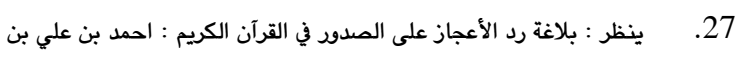

$$
\begin{aligned}
& 86 \text { : عثمان العثمان } \\
& \text { 28. } \\
& \text { دراسات في علم البديع : مصطفى السيد جبر : } 132
\end{aligned}
$$

المثل السائر في أدب الكاتب والشاعر :ضياء الدين محمد بن محمد بن عبدالكريم

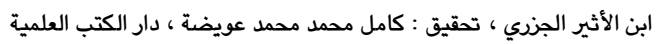

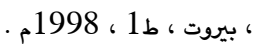

المحيط في اللغة : الصاحب بن عباد ، تحقيق : محمد حسن آل ياسين ، عالم الكتب

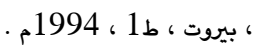

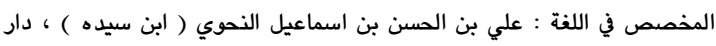

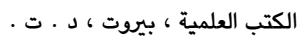

مدخل إلى الدلالة الحديثة : عبدالمجيد جحفة ، دار توبقال ، المغرب ، ط1 ، كلدوت . 2000

معجم المصطلحات العربية في اللغة والأدب : مجدي وهبة ، و : كامل المهندس ،

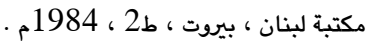

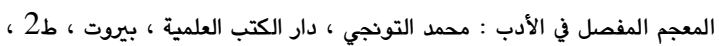
1999م

معجم مقاييس اللغة : أحمد بن فارس ، تحقيق : إبراهيم شمس الدين ، دار الكتب

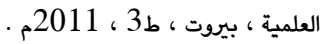

المنزع البديع في تجنيس أساليب البديع : أبو القاسم السجلماسي ، تحقيق : علال ، بلال

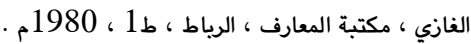

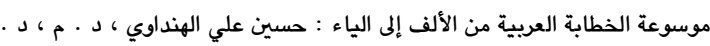
.

نحو النص : عثمان أبو زنيد ، عالم الكتب الحديث ، إربد ، ط1 ، 2010م .

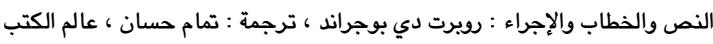

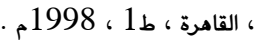

النقد الأدبي أصوله ومناهجه : سيد قطب : دار الشروق ، القاهرة ، ط8 ، 2003م

النقد الجمالي وأثره في النقد العربي : روذ غريّب ، دار العلم للملايين ، بيروت ،

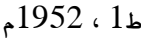

نقد النثر : قدامة بن جعفر ، دار الكتب العلمية ، بيروت ، 1980م .

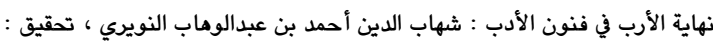

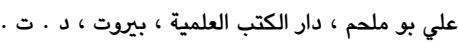

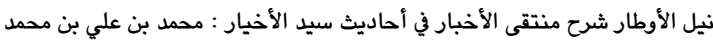
الشوكاني ، من إصدارات وزارة الشؤون الإسلامية والأوقاف والدعوة

$$
\text { والإرشاد ، السعودية ، د ـ ت ت من إهدات وزارة }
$$

وشي الربيع بألوان البديع في ضوء الأساليب العربية : عائشة حسين فريد ، دار ، دار قباء للطباعة والنشر ، القاهرة ، 2000م .

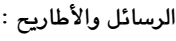

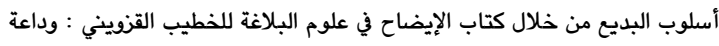

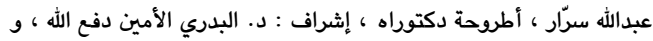

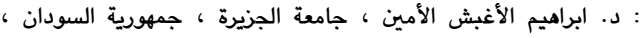
2014

البلاغة النبوية في الأربعين النووية : خالد عبد العزيز الزويع ، رسالة ماجستير ، إشراف : د. عبدالرحمن عطا المنان ، جامعة أم درمان الإسلامية ،

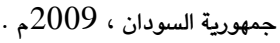
بلاغة رد الأعجاز على الصدود في القرآن : أحمد بن علي بن بل عثمان العثمان ، رسالة

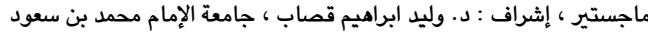

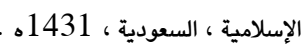


اسماعيل ، مثنى محمول و يونس ، إباء رشيد / مجلة العلوم الانسانية لجامعة زاخو، مجلد:9 ، العدد:1 ، ص 131- 140 ، ناذار - 2021.

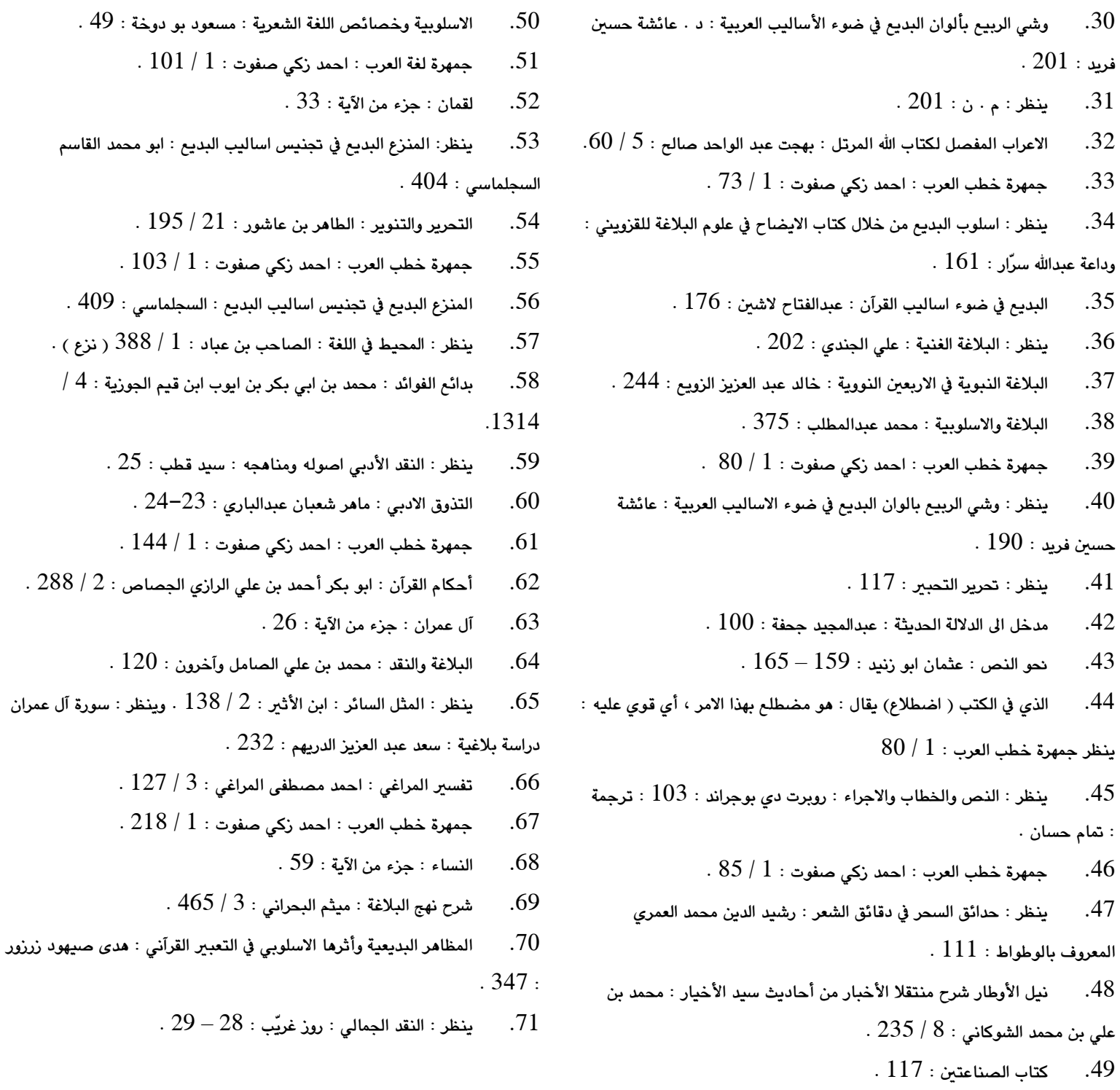


كوتارخاندن دهيته هزمارتن ز هونه رين هه ره كه فن ين ويزه ى ، و ج كومه ل زى بى به هر نين ئه وين كو ميزويا خو باراستبن هـ تا فى سه رده مى دا ، زبهر رولى

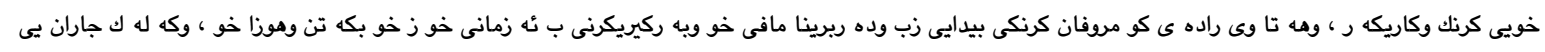

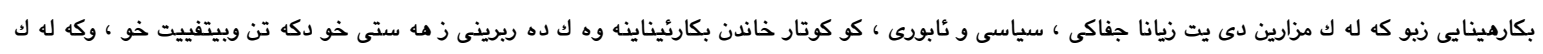

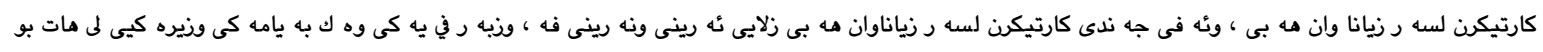

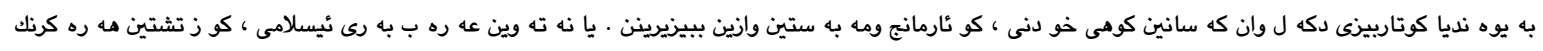

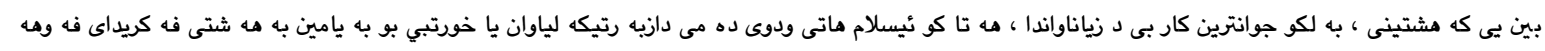

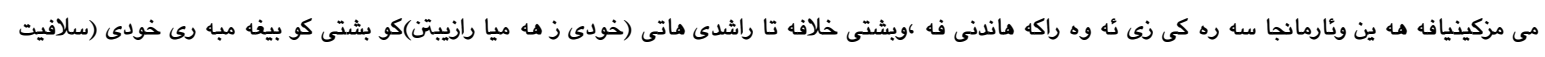

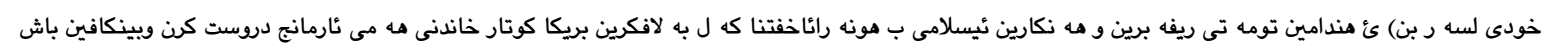

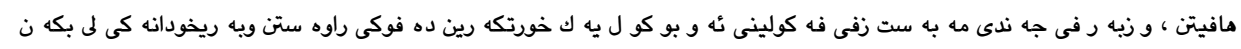

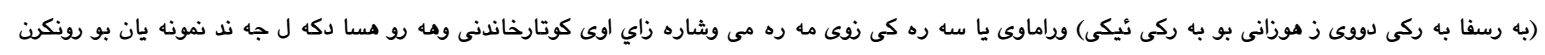
وشلوفه كرن مه ره م زوى . يَهيثيّن سهرهكى: كوتار ، بركادووى (به رسف)، بركا ئيكى (سينكى)، خيلافه ت، واته.

The eloquence of responding to miracles on the breasts in the sermons of the Rightly Guided Caliphs (may God be pleased with them)

\section{Abstract:}

The religious public speaking is one of the oldest arts of literature, and one of the societies whose monument have been preserved until this day is not without its community. Because of its functional role and effective influence, a human relied on it to defend himself or his tribe with his tongue. He used to resort to it in many situations, such as exhortation to fight, calling for reconciliation, the judiciary, and other matters of social, political and economic life, so rhetoric was used in it as a tool to express what was wanted, and it had a great impact on the lives of individuals and societies, negatively or positively. The preacher's contact with the listener, which was adopted by the high-class nations and peoples as a way to persuade and provoke people; To adopt the goals and objectives of the preacher. As for the Arab nation before Islam, it was one of the finest things it reached at that time, but was the essence of their lives, until I shade it in a new era with the advent of Islam. In the speech of the Prophet's era, its importance increased in the era of early Islam due to its strong connection with the divine messages as well as the preachers. Being their first tool in reporting. The Rightly Guided Caliphs (PBUTH) after the Prophet (PBUH) directed the members of the nation and spread the teachings of Islam through the art of public speaking. In addition, they had knights with their methods and phrases full of wonderful colors; Therefore, the aim of this research was to stand at one of the verbal enhancers, using (the response to First Hemistich and second Hemistich as a means to identify the secrets of the meanings that these sermons brought by studying and analyzing examples of them to find out how to employ this verbal enhancer in rhetoric.

Keywords: Religious public speaking-Second Hemistich - First Hemistich - Caliphs - Meaning. 